\title{
Mild thermotherapy and hyperbaric oxygen enhance sensitivity of TMZ/PSi nanoparticles via decreasing the stemness in glioma
}

\author{
Xiaofan Zeng, Qi Wang, Xuan Tan, Le Jia, Yuwei Li, Mingdi Hu, Zhijie Zhang, Xicheng Bai, Yanhong Zhu* (0) \\ and Xiangliang Yang ${ }^{*}$
}

\begin{abstract}
Background: Glioma is a common brain tumor with a high mortality rate. A small population of cells expressing stem-like cell markers in glioma contributes to drug resistance and tumor recurrence.

Methods: Porous silicon nanoparticles (PSi NPs) as photothermal therapy (PTT) agents loaded with TMZ (TMZ/ PSi NPs), was combined with hyperbaric oxygen (HBO) therapy in vitro and in vivo. To further investigate underlying mechanism, we detected the expression of stem-like cell markers and hypoxia related molecules in vitro and in vivo after treatment of TMZ/PSi NPs in combination with PTT and HBO.

Results: $\mathrm{NCH}-421 \mathrm{~K}$ and $\mathrm{C} 6$ cells were more sensitive to the combination treatment. Moreover, the expression of stem-like cell markers and hypoxia related molecules were decreased after combination treatment. The in vivo results were in line with in vitro. The combination treatment presents significant antitumor effects in mice bearing C6 tumor compared with the treatment of TMZ, PTT or TMZ/PSi NPs only.
\end{abstract}

Conclusion: These results suggested the TMZ/PSi NPs combined with HBO and PTT could be a potential therapeutic strategy for glioma.

Keywords: Glioma, Photothermal therapy, Hyperbaric oxygen, Porous silicon nanoparticles, Stemness

\section{Background}

Gliomas are the most common brain tumors with a high mortality rate found in humans in Europe and the US [1, 2]. Surgery followed by chemotherapy or radiotherapy is the standard therapy strategy for glioma [3]. However, patients still exhibit a poor prognosis, with a mean survival time lower than 15 months $[4,5]$. Increasing evidences have indicated the existence of a small population of glioma cells with stem cell properties, referred to as glioma stem-like cells, which contribute to therapy resistance, poor prognosis, and tumor recurrence $[6,7]$.

Hypoxia is an important characteristic of solid tumors and plays a significant role in stem-like cell development

\footnotetext{
*Correspondence: yhzhu@hust.edu.cn; nanomedicine@mail.hust.edu.cn National Engineering Research Center for Nanomedicine, College of Life Science and Technology, Huazhong University of Science and Technology, No. 1037 Luoyu Road, Wuhan 430074, People's Republic of China
}

[8]. Hypoxia can lead to breast cancer stem cell (CSC) expansion [9]. Hypoxia significantly favored ADMSC proliferation and preserved the expression of stemness genes, i.e. Nanog and SOX2 [10]. Hypoxia is also a distinct feature in glioma. In the absence of serum, hypoxia induced C6 cells to dedifferentiate to a CSCs phenotype [11]. Clinically used anti-tumor drug TMZ against glioma increases the medial survival of the patient for only several months, which may happen due to chemoresistance under the hypoxia related environment $[12,13]$. $\mathrm{HBO}$ could overcome the hypoxia microenvironment in solid tumor and increase the sensitivity of tumor cell to chemotherapy $[14,15]$.

Thermotherapy has long been used as a treatment method for cancer, but it is difficult to treat patients without damaging healthy cells. Among different thermotherapies, mild thermotherapy $\left(40-44{ }^{\circ} \mathrm{C}\right)$ can enhance the drug effects and is more acceptable by patients $[16$,

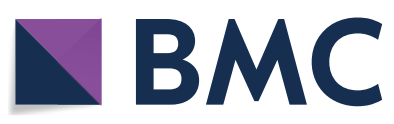

(c) The Author(s) 2019. This article is distributed under the terms of the Creative Commons Attribution 4.0 International License (http://creativecommons.org/licenses/by/4.0/), which permits unrestricted use, distribution, and reproduction in any medium, provided you give appropriate credit to the original author(s) and the source, provide a link to the Creative Commons license, and indicate if changes were made. The Creative Commons Public Domain Dedication waiver (http://creativecommons.org/ publicdomain/zero/1.0/) applies to the data made available in this article, unless otherwise stated. 
17]. Heating rodent tumors at $40-42{ }^{\circ} \mathrm{C}$ was found to increase the blood flow and partial pressure of oxygen in the tumors. The increased blood flow caused by mild heat may improve the delivery of chemotherapy drugs to tumor cells [18]. Combining photothermal therapy (PTT) with chemotherapy is an interesting research direction in nano-medicine [19]. Nanodrug-mediated thermotherapy can eliminate CSCs [20]. Porous silicon (PSi) can be utilized as a therapeutic agent that generates mild heat upon exposure to NIR light [21]. Thermotherapy based on PSi under NIR light irradiation in combination with chemotherapy is an efficient technique to reduce cancer cells resistance [22-24]. Here, we hypothesized that the mild thermotherapy caused by PSi combined with $\mathrm{HBO}$ could increase the oxygen supply in the tumors and enhance chemosensitivity in tumor stem cells.

In this study, PSi loaded with TMZ for chemo-photothermal therapy, was further combined with HBO therapy to reduce self-renewal of glioma stem-like cells and inhibit glioma growth (Scheme 1).

\section{Methods}

\section{Materials}

The boron-doped p-type silicon wafers were obtained from Virginia Semiconductor, Inc. (VA, USA) [15]. Drug TMZ was purchased from Aladdin Reagent Co. Ltd. (Shanghai, China). Other chemicals were of analytic grade. The experimental hyperbaric oxygen ( $\mathrm{HBO}$ ) animal chamber was purchased from Weifang Huaxin Oxygen Industry Co., Ltd (Weifang, China).

Rat glioma C6 cell line was preserved in our lab. Glioma stem cell line $\mathrm{NCH}-421 \mathrm{~K}$ used in this study was kindly provided by the Neurosurgery Laboratory of Tongii Medical College, Huazhong University of Science and Technology. BALB/c-nude mice (male, 16-18 g) were purchased from Beijing Wei Tong Li Hua experimental animal Co., Ltd (Beijing, China). The animal protocol was approved by the Animal Experimentation Ethics Committee of College of Life Science and Technology, Huazhong University of Science and Technology.

\section{Preparation of PSi and TMZ/PSi NPs}

Preparation of PSi NPs was performed as described previously [25]. TMZ/PSi NPs were prepared according our report with a little modification [15]. Briefly, TMZ dissolved in 5\% phosphoric acid/methanol solution was added into the NPs under stirring overnight. TMZ-loaded PSi NPs (TMZ/PSi NPs) were obtained by ultrafiltration centrifugation and washed three times. Ultraviolet spectrophotometer was used to measure the amount of TMZ/PSi NPs.

\section{Characterization of PSi and TMZ/PSi NPs}

The size and morphology were characterized by TEM (JEM-2010; JEOL, Tokyo, Japan). An 808 nm NIR laser (Changchun radium Photoelectric Technology Co., Ltd.,

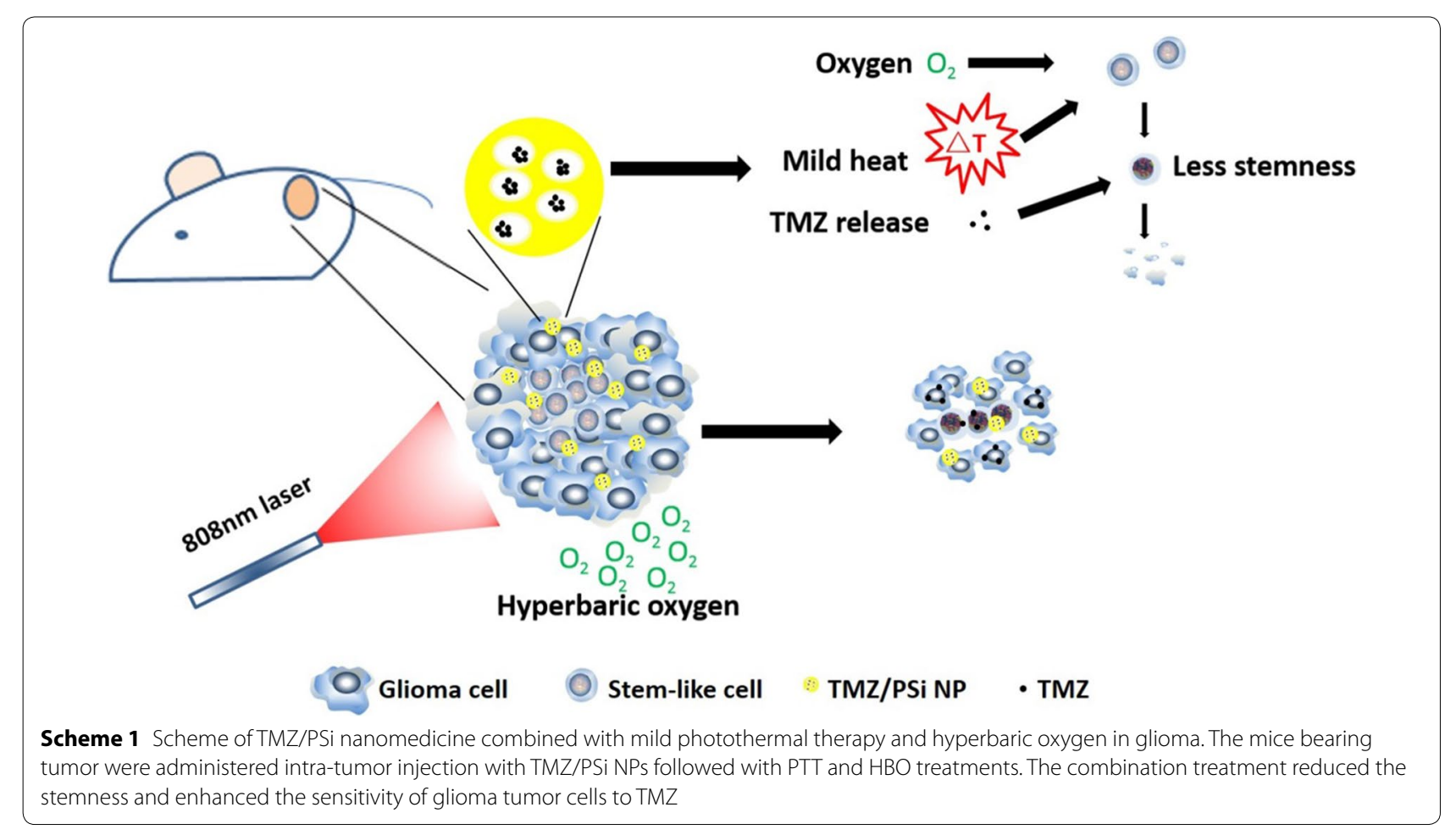


China) was used to investigate the photothermal conversion capability of PSi and TMZ/PSi NPs.

\section{Drug release test}

TMZ release at $37{ }^{\circ} \mathrm{C}$ or $42{ }^{\circ} \mathrm{C}$ was performed according to previous report $[15,26]$.

\section{HBO treatment}

HBO therapy was performed at a pressure of 2.5 ATM according to our previous work [14].

\section{Photothermal therapy (PTT) treatment}

Photothermal therapy (PTT) treatment was conducted with $808 \mathrm{~nm}$ NIR laser at $0.6 \mathrm{~W} / \mathrm{cm}^{2}$ for $20 \mathrm{~min}$. During irradiation, the temperature was monitored using thermography (E50, FLIR Systems Inc, USA). After treatment with TMZ/PSi, PTT was carried out for $20 \mathrm{~min}$ followed by $\mathrm{HBO}$ treatment in the combination treatment (PTT + HBO) groups.

\section{Cell culture}

$\mathrm{NCH}-421 \mathrm{~K}$ cells were cultured in DMEM/F12 medium (Hyclone) supplemented with 20\% BIT (Stemcell Technologies), $10 \mathrm{ng} / \mathrm{mL}$ basic fibroblast growth factor (bFGF, Peprotech), $10 \mathrm{ng} / \mathrm{mL}$ epidermal growth factor (EGF, Peprotech). C6 cells were cultured with DMEM medium (Hyclone) supplemented with 10\% FBS (Gibco).

\section{Cell viability assay of TMZ}

Different dose of TMZ (50, 100, 200, 400, 800, $1600 \mu \mathrm{M})$ were used to test cell viability. $\mathrm{NCH}-421 \mathrm{~K}$ or C6 Cells $\left(8 \times 10^{3}\right.$ cells/well $)$ were plated into 96 -well plates and incubated at $37{ }^{\circ} \mathrm{C}$ with $5 \% \mathrm{CO}_{2}$ overnight before adding TMZ. Cell viability was detected at 24,48 and $72 \mathrm{~h}$ using the CCK-8 after different treatments respectively.

\section{Evaluation of TMZ/PSi on cell viability under different treatments}

One critical toxicity dose of TMZ $(400 \mu \mathrm{M})$ was used to assess the TMZ/PSi NPs effects on cancer stem-like cells. Cells were divided into PSi, TMZ or TMZ/PSi NPs (with or without PTT) groups at the different oxygen concentrations, respectively. $\mathrm{NCH}-421 \mathrm{~K}$ cells and $\mathrm{C} 6$ cells were cultured in normoxia and then treated under $100 \% \mathrm{O}_{2}$ for $90 \mathrm{~min} /$ day after adding drugs. After incubation for $72 \mathrm{~h}$, SRB method was used to evaluate the cell viability [15].

\section{Assay of colony formation}

$\mathrm{NCH}-421 \mathrm{~K}$ cells at a density of $2.5 \times 10^{5}$ cells/well were plated into 12-well plates and cultured overnight. Cells were treated with $100 \mu \mathrm{M}$ TMZ or TMZ/PSi NPs for $24 \mathrm{~h}$. Then the cells were harvested and countered, plated at a density of $2 \times 10^{4}$ cells/well into 24 -well plates for shape observation and the surviving fraction in 24-well plates was taken a picture on day 1,4 and $7.1 \times 10^{2}$ cells/ well was plated into 96-well plates for countering colony number and the number of tumorspheres in each well was recorded on day 7 .

\section{mRNA and Western-blot analysis}

For qRT-PCR assays, cell and tumor tissue RNA was extracted according the manual of PrimeScript RT reagent Kit (Takara Biotechnology Co., Ltd., China) and Primers were present in Additional file 1: Table S1. The StepOnePlus Real Time PCR System (Applied Biosystems, Foster City, CA, USA) was used. The resulting data were analyzed with the comparative cycle threshold (CT) value for relative gene expression quantification relative to GAPDH.

Cell proteins were extracted using normal method [7]. After blocking, antibody against HIF-1 $\alpha$ (Abcam, UK), Nestin, SOX2, VEGF and GAPDH (Proteintech, China), were added, respectively.

\section{In vivo antitumor effects of combination treatment}

To establish tumor bearing model, $3 \times 10^{6} \mathrm{C} 6$ cells were subcutaneously inoculated into a nude mouse. When tumor volume was above $75 \mathrm{~mm}^{3}$, the mice were randomly divided into six groups: the control group, PSi group, TMZ group, PTT group, TMZ/PSi group, and TMZ/PSi combined with PTT and HBO group respectively. According to our previous report, $\mathrm{HBO}$ alone has no effects on C6 glioma [15]. Therefore, HBO alone group was not included in this study. Then the mice bearing tumors were intratumor injected with TMZ or TMZ/ PSi NPs (5 mg/kg TMZ) followed with PTT and HBO treatment on day $1,4,7$, and 10 in the related groups, respectively. The sizes of the tumors were recorded every 2 days. The formula: tumor volume $\left(\mathrm{mm}^{3}\right)=0.5 \times$ length $(\mathrm{mm}) \times[\text { width }(\mathrm{mm})]^{2}$, was used to calculate the tumor volume. At the end of animal experiment, the mice were sacrificed, and tumor tissues and other organs were collected.

\section{Immunohistochemistry and mRNA analysis of tumor tissue} The immunohistochemistry analysis was performed. Rabbit polyclonal Nestin and SOX2 antibody (Servicebio, China) were used to stain stemness marker of the tumor tissue, respectively. Rabbit polyclonal HIF-1 $\alpha$, and VEGF antibody (Servicebio, China) were used to stain hypoxia marker and vascularization of the tumor tissue, respectively. Rabbit monoclonal Ki-67 antibody (Servicebio, China) was used for analyzing cell proliferation.

Tumor tissue RNA was extracted according the manual of PrimeScript RT reagent Kit (Takara Biotechnology Co., Ltd., China) for qRT-PCR assays. 


\section{Statistical analysis}

The data were expressed as mean \pm SEM. Statistical significance in all experiment was determined using oneway ANOVA followed by a Student's test for multiple comparison tests. Statistical analysis was analyzed using statistical software (IBM SPSS Statistics 20, USA).

\section{Results and discussion}

\section{Characterization, photothermal effect and in vitro drug} release

The irregular shapes of PSi and TMZ/PSi NPs were shown and the average size of PSi and TMZ/PSi NPs was about $90 \mathrm{~nm}$ and $140 \mathrm{~nm}$ under transmission electron microscope respectively (Fig. 1a, b). The DLS sizes of NPs remained stable for 1 week at room temperature (Additional file 1: Figure S1). The surface temperature of PSi and PSi/TMZ after exposure to $808 \mathrm{~nm}$ NIR laser at $0.6 \mathrm{~W} / \mathrm{cm}^{2}$ was measured using a thermometer (Fig. 1c). The temperature reached to $42{ }^{\circ} \mathrm{C}$ approximately upon NIR laser irradiation and remained the temperature thereafter. TMZ release was about $80 \%$ within $24 \mathrm{~h}$ (Fig. 1d). An increasing release was observed at the beginning of $20 \mathrm{~min}$ after exposure to NIR laser irradiation, which illustrates that hyperthermia could accelerate drug release.

\section{Effects of TMZ and TMZ/PSi NPs in combination with PTT and $\mathrm{HBO}$ on stem-like cell viability}

The stem-like cell character (stemness) has been thought to be closely associated with tumor progression and therapeutic resistance [27]. Glioma stem cells (GSCs) are increasingly recognized as playing important roles in the chemoresistance of glioma [28]. To demonstrate tumor stem-like cell viability affected by TMZ/PSi or TMZ, glioma stem cell line $\mathrm{NCH}-421 \mathrm{~K}$ (GSCs) were cultured in vitro under normoxia condition. As shown in Fig. 2a and Additional file 1: Figure S2, NCH-421K cell viability was significantly decreased when treated with $\mathrm{TMZ}$ at $400 \mu \mathrm{M}$.

Furthermore, the effect of TMZ/PSi NPs containing $400 \mu \mathrm{M}$ of TMZ with or without HBO and PTT treatments on GSCs and C6 cells was studied (Additional file 1: Figure S3). The decrease of cell viability treated with TMZ/PSi NPs was observed after combination treatment with PTT and HBO compared to that without PTT or HBO treatment (Fig. 2b). Similarly, after treatment with same dose of TMZ/PSi, cell viability decreased significantly compared to free TMZ alone. Compared with TMZ/PSi, the cell viability was decreased both in TMZ/ $\mathrm{PSi}+\mathrm{HBO}$ group $(\mathrm{P}=0.318)$ and in TMZ/PSi $+\mathrm{PTT}$ group $(\mathrm{P}=0.003)$, whereas the cell viability was more significantly decreased in TMZ/PSi + PTT + HBO ( $\mathrm{P}$ $=0.000063)$ group than that in other groups. Consistent with results in $\mathrm{NCH}-421 \mathrm{~K}$ cells, PTT and $\mathrm{HBO}$ increased the sensitivity of TMZ/PSi against glioma stem-like C6 cells (Additional file 1: Figure S4).

In our study, although the amount of TMZ loaded into PSi NPs is the same with free TMZ in the treatment, nanoparticle-delivered TMZ exerted much higher cytotoxicity. Thermotherapy was thought to increase drug uptake into cells [22]. Hyperoxia can resensitize chemoresistant of human glioblastoma cells to TMZ [29]. Moreover, toxicity of combination treatment on morphology of NCH-421K was significant too. Tumorspheres of $\mathrm{NCH}-421 \mathrm{~K}$ were fragmented significantly after treating with TMZ/PSi + PTT + HBO compared to other groups for $72 \mathrm{~h}$ (Fig. 2c, d). Therefore, PTT and $\mathrm{HBO}$-adjuvanted with TMZ/PSi NPs enhance the effects on viability of glioma stem-like cells.
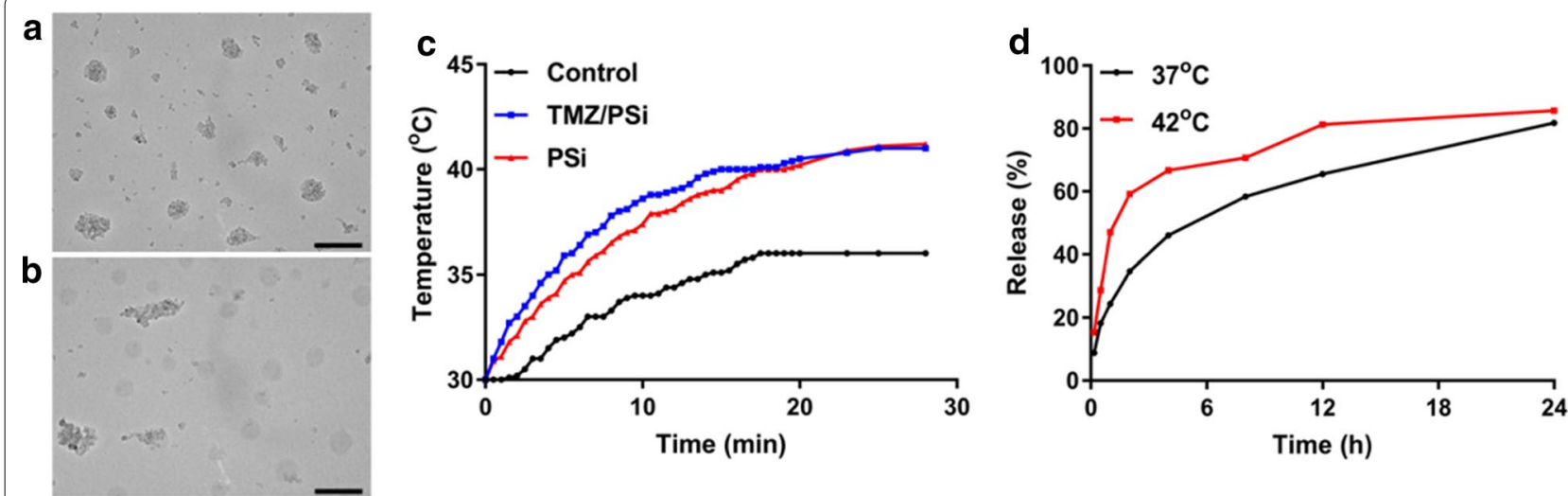

Fig. 1 Characterization, photothermal effect and in vitro drug release. a, b TEM images of PSi and TMZ/PSi, bar: 200 nm. c Temperature increase curve of PSi and TMZ/PSi. $\mathbf{d}$ Drug release of TMZ/PSi at different temperatures 


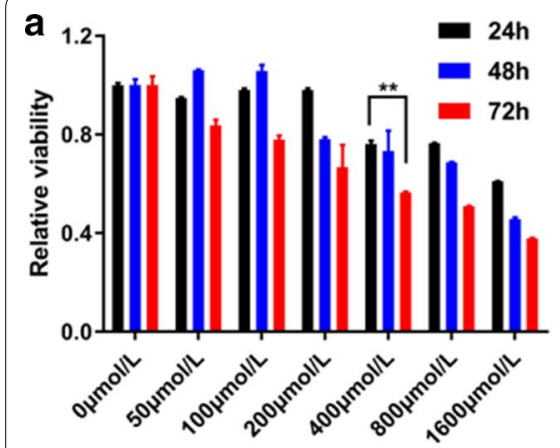

d

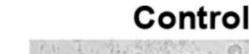

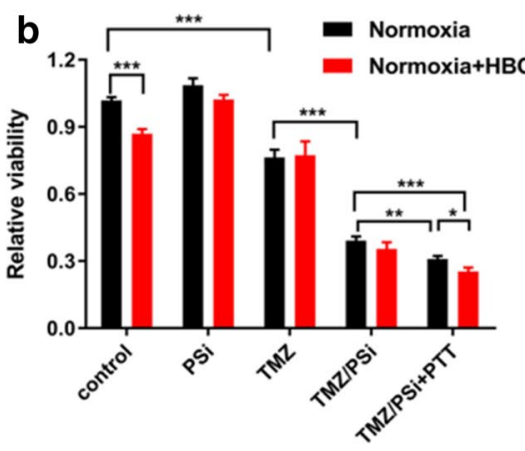

TMZ

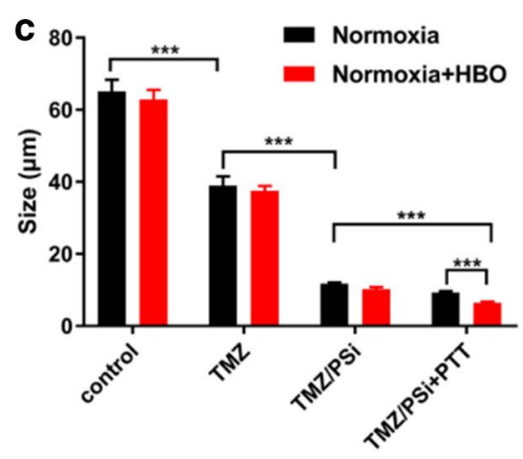

TMZ/PSi
TMZIPSi+PTT
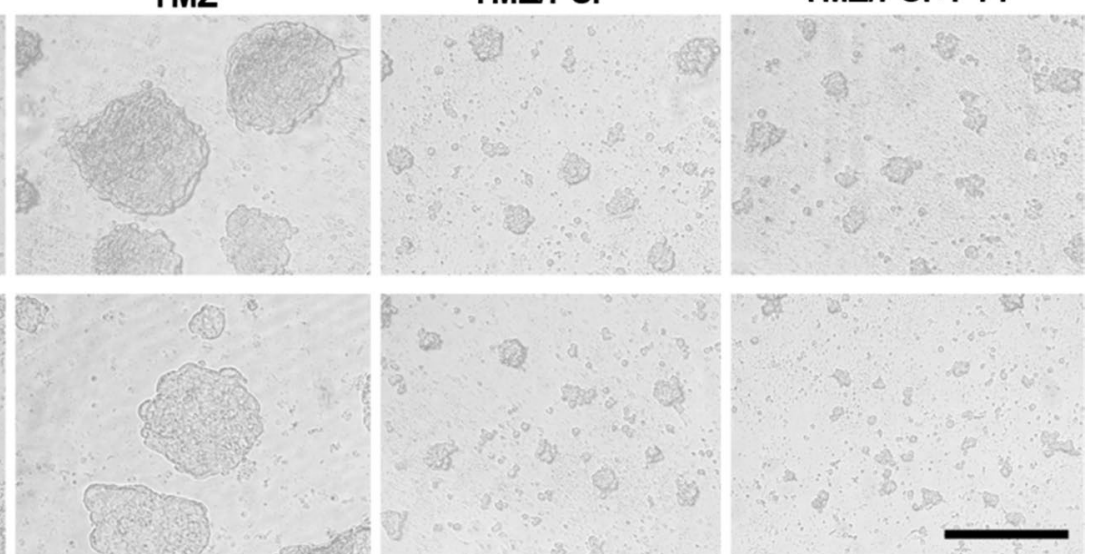

Normoxia $+\mathrm{HBO}$

Fig. 2 Effects of TMZ and TMZ/PSi NPs combined with PTT and HBO on glioma stem cell viability. a Viability of NCH-421K cells after treatments with different TMZ concentrations $\left(n=5\right.$; $\left.{ }^{* *} P<0.01\right)$. b Viability of NCH-421K cells after different treatments $\left(n=5 ;{ }^{*} P<0.05,{ }^{* *} P<0.01\right.$, $\left.{ }^{* * *} P<0.001\right)$. c, d Tumorsphere size and shape after different treatments $\left(n=5 ;{ }^{* *} \mathrm{P}<0.001\right)$. NCH-421K cells were cultured in normoxia and then treated under $100 \% \mathrm{O}_{2}$ for $90 \mathrm{~min} /$ day after adding drugs. After incubation for $72 \mathrm{~h}$, CCK- 8 or SRB method was used to evaluate the cell viability. Bar: $50 \mu \mathrm{m}$

\section{Colony formation of $\mathrm{NCH}-421 \mathrm{~K}$ cells after different treatments}

Spheroid colony formation is a useful method to identify glioma stem cells (GSCs) [30]. In this study, we determined the effect of TMZ/PSi combined with PTT and $\mathrm{HBO}$ on GSC colony formation for 7 days (Fig. 3a, b, Additional file 1: Figure S5). Although TMZ alone attenuated GSC colony formation and tumorsphere growth, the remained GSCs were able to form tumorspheres. However, TMZ/PSi combined with PTT and HBO could inhibit GSCs self-renewal completely compared to TMZ alone (Fig. 3c). These studies demonstrate that TMZ/PSi combined with PTT and HBO can significantly suppress the clonogenic capacity of GSCs.

\section{mRNA and protein analysis in NCH-421K cells after different treatments}

To further investigate the underlying mechanism how TMZ/PSi combined with PTT and HBO eliminated GSCs, master regulators for the self-renewal and stemness maintenance of GSCs (SOX2 and Nestin) and hypoxia related molecules HIF-1 $\alpha$ [31] and VEGF were evaluated. We investigated the expression of SOX2, Nestin, HIF- $1 \alpha$ and VEGF through qRT-PCR and Western blot assays. As shown in Fig. 4, compared with the control group, TMZ increased the expression of stemness and hypoxia related factors (such as SOX2, Nestin, VEGF), which was caused closely related to chemo-resistance [32]. The expression of SOX2, HIF- $1 \alpha$, and VEGF were decreased in the TMZ/ PSi group, which indicates nanomedicine TMZ/PSi can amend the drug resistance. $\mathrm{HBO}$ can improve the hypoxia in tumor microenvironment, thus the expression of HIF- $1 \alpha$ and VEGF was decreased after treatment. All factor expressions were significant decreased in the combination treatment of PTT and $\mathrm{HBO}$ and TMZ/PSi, indicating that PTT and HBO can be as adjuvants for TMZ/PSi. The down-regulation of protein levels was not significant, whereas the decrease tendency of all factors expression was existed in the combination treatment compared to TMZ/PSi. The mRNA analysis in $\mathrm{NCH}-421 \mathrm{~K}$ cells after treating with $\mathrm{TMZ} / \mathrm{PS} \mathrm{i}+\mathrm{HBO}$ 


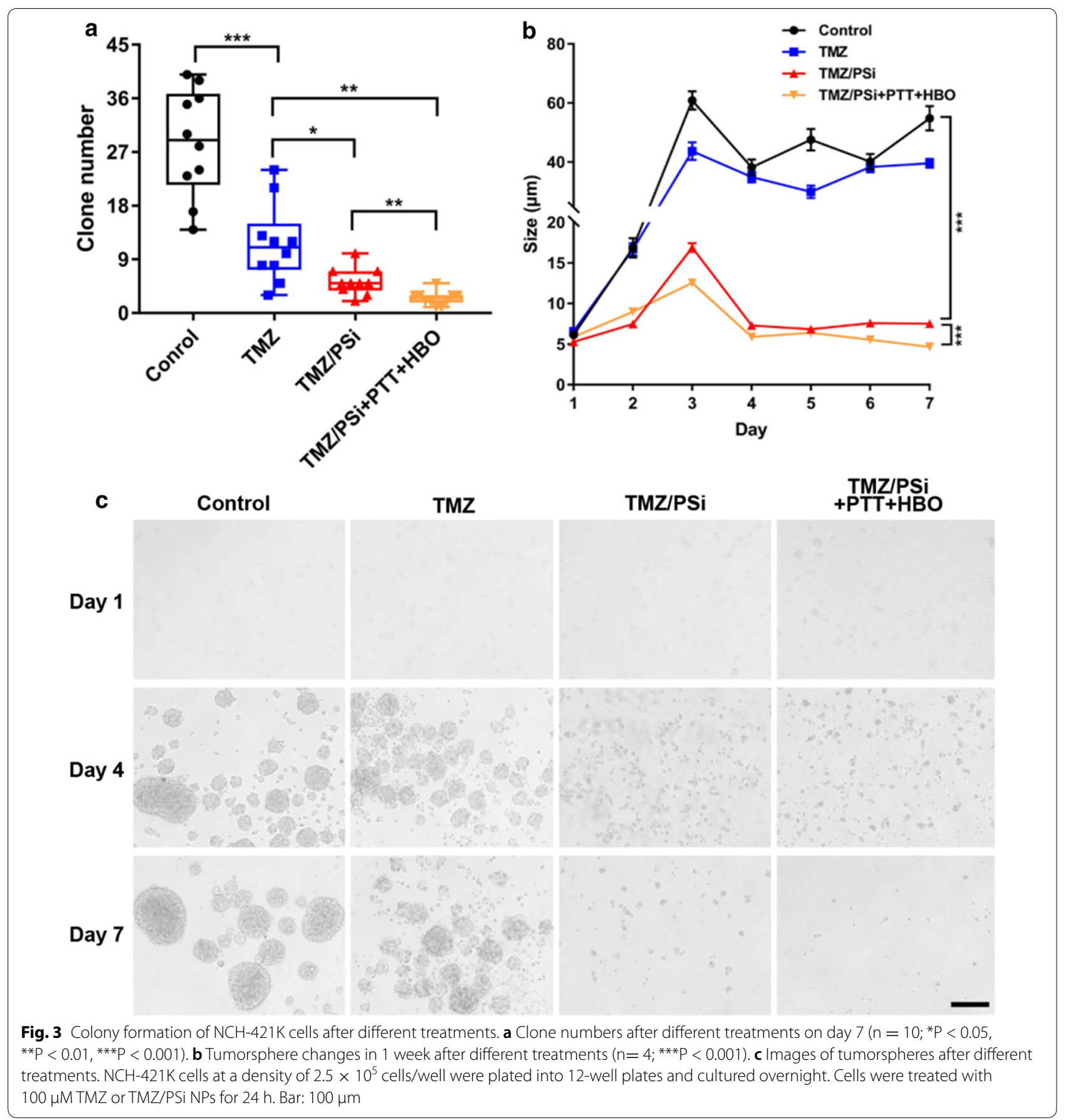

or TMZ/PSi + PTT were shown in Additional file 1: Figure S6. As shown in figure, no significant differences were observed in SOX2 $(\mathrm{P}>0.05)$ and Nestin $(\mathrm{P}>0.05)$ compared with TMZ/PSi. However, all 4 factor expressions were significantly decreased in the combination treatment of TMZ/PSi $+\mathrm{HBO}+\mathrm{PTT}$. This finding demonstrated that PTT and $\mathrm{HBO}$ alleviates the hypoxia in tumorspheres and increase the sensitivity of GSC to TMZ/PSi.

Effects of TMZ/PSi combined with PTT and HBO on C6 cells To further investigate the effection of TMZ/PSi combined with PTT and HBO, C6 glioma cells were used. C6 glioma cells have properties in common with glioma stem cells $[33,34]$. Most of the C6 cells are 

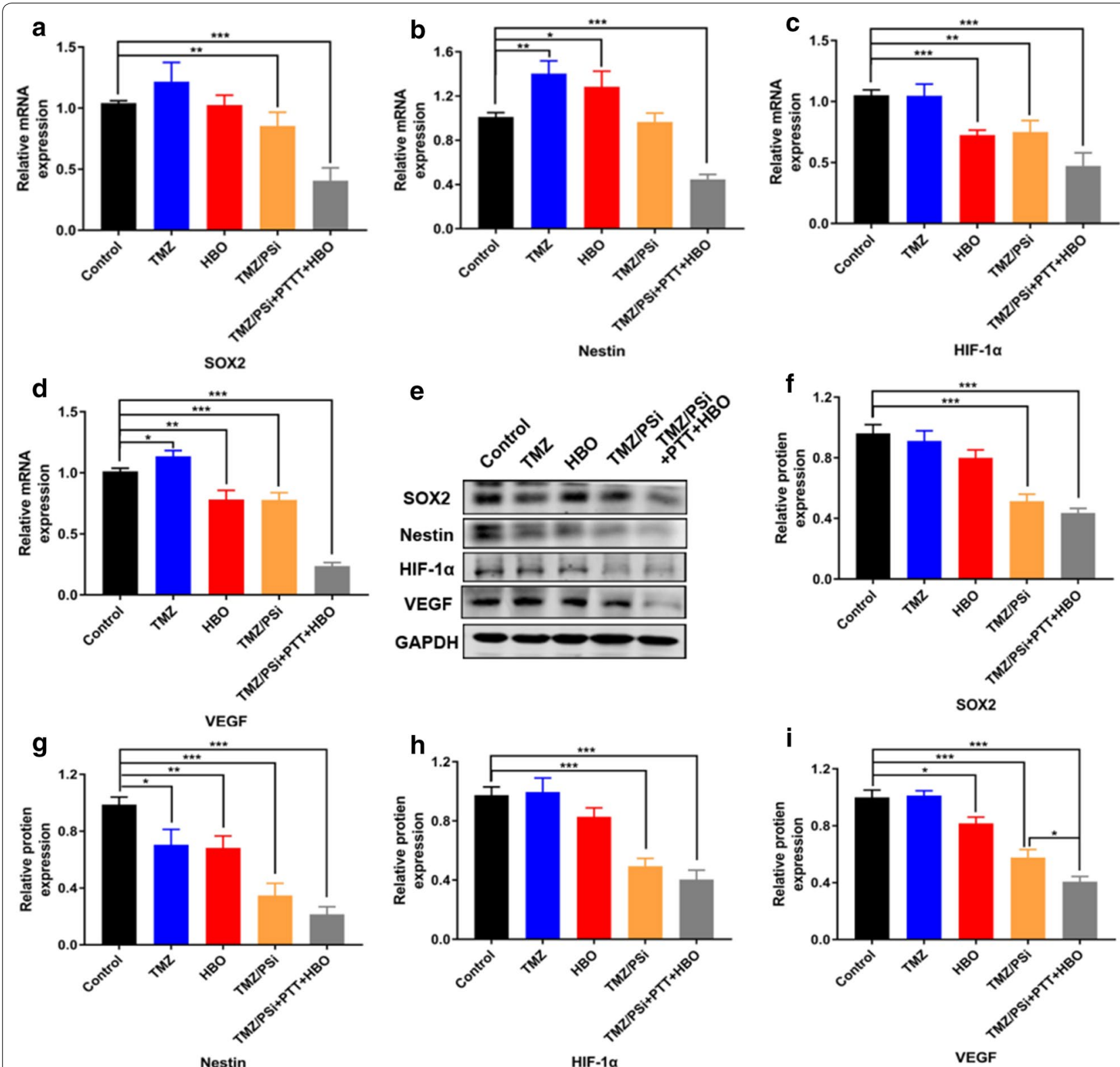

Fig. 4 mRNA and protein analysis in NCH-421 K cells after different treatments. a-d mRNA changes of SOX2, Nestin, HIF-1a and VEGF in NCH-421 K cells after different treatments. NCH-421 K cells were treated with $400 \mu \mathrm{M} \mathrm{TMZ}$ for $72 \mathrm{~h}\left(\mathrm{n}=3\right.$; ${ }^{*} \mathrm{P}<0.05,{ }^{* *} \mathrm{P}<0.01$, ***P $\left.<0.001\right)$. e Western blot analysis of SOX2, Nestin, HIF-1 a and VEGF in NCH-421 K cells after different treatments. NCH-421 K cells were treated with $400 \mu \mathrm{MTMZ}$ for $24 \mathrm{~h}$. f-i The relative protein content of SOX2, Nestin, HIF-1 a and VEGF in NCH-421K cells after different treatments $\left(n=3 ;{ }^{*} P<0.05\right.$, **P $<0.01$, ,*** $\left.<<0.001\right)$

cancer stem-like cells with in vitro characteristics of self-renewal [35]. Therefore, C6 cells were chosen to further study the combination therapy effects of TMZ/ $\mathrm{PSi}+\mathrm{PTT}+\mathrm{HBO}$. As shown in Fig. 5, mRNA levels of SOX2, Nestin, HIF- $1 \alpha$ and VEGF in C6 cells after combination treatment of TMZ/PSi + PTT + HBO were significantly decreased compare to the TMZ/PSi group $\left({ }^{* * *} \mathrm{P}<0.01 ;{ }^{* * * *} \mathrm{P}<0.001\right)$. Western blot results of SOX2,
Nestin, HIF- $1 \alpha$ and VEGF expression were decreased compare to the control group $\left({ }^{* *} \mathrm{P}<0.01\right.$; $\left.{ }^{* * *} \mathrm{P}<0.001\right)$. All factors showed significantly difference, which is similar to the results in $\mathrm{NCH}-421 \mathrm{~K}$ after different treatments. 

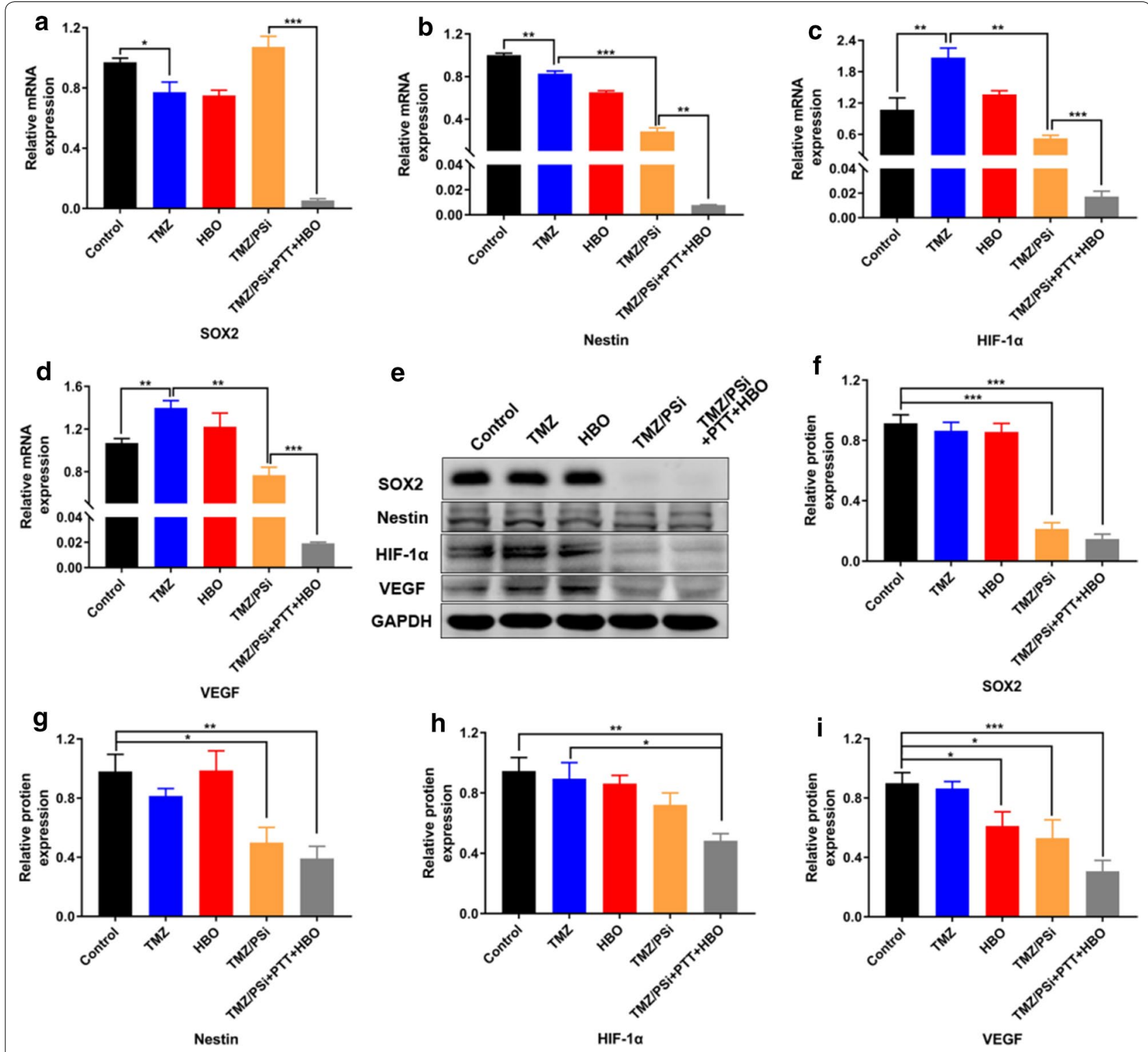

Fig. 5 Effects of TMZ/PSi combined with PTT and HBO on C6 cells after different treatments. a-d mRNA changes of SOX2, Nestin, HIF-1a and VEGF in C6 cells after different treatments $\left(n=3 ;{ }^{* P}<0.05,{ }^{* * P}<0.01,{ }^{* *} \mathrm{P}<0.001\right)$. C6 cells were treated with $400 \mu M T M Z$ for $72 \mathrm{~h}$. e Western blot analysis of SOX2, Nestin, HIF-1a and VEGF in C6 cells after different treatments. C 6 cells were treated with $400 \mu \mathrm{M} \mathrm{TMZ}$ for $24 \mathrm{~h}$. $\mathbf{f}-\mathbf{i}$ The relative protein content of SOX2, Nestin, HIF-1 a and VEGF in C6 cells after different treatments $\left(n=3 ;{ }^{*} P<0.05,{ }^{* *} P<0.01,{ }^{* * *} P<0.001\right)$

Antitumor effects of TMZ/PSi NPs in combination with PTT and $\mathrm{HBO}$

Glioma is a solid tumor characterized with hypoxia environment [26]. Tumor stem cells exhibit in hypoxic niches are known to be a key cause of the progression, metastasis and relapse [12]. Efficacy of hyperbaric oxygen therapy in combination with mild heat improved the anti-tumour effects of carboplatin [22]. In light of this, mild PTT and external nanodrug in treating glioma in vivo combined with $\mathrm{HBO}$ was performed. In this study, we choose C6 stem-like cells to establish tumor bearing mouse model to investigate the effects of combination treatment.

The PSi NPs are well known to absorb IR energy and transfer it in the form of heat [36]. Upon NIR irradiation instantly after injection, the local tumor temperature gradually increased and reached about $43{ }^{\circ} \mathrm{C}$ (Fig. 6a, b), which was helpful to kill tumor cells. The mild hyperthermia regimes can avoid the massive necrosis that would be associated with high temperatures [28]. Therefore, PSi is an acceptable mild 

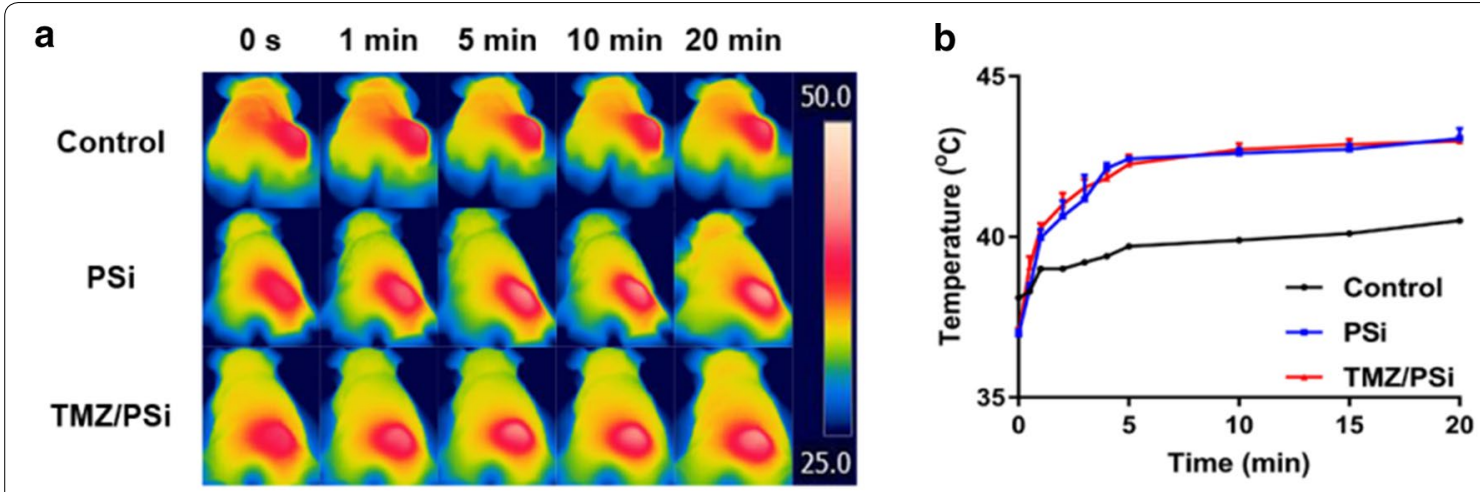

C

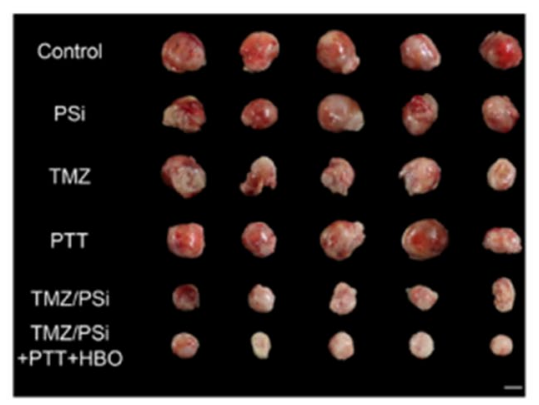

d

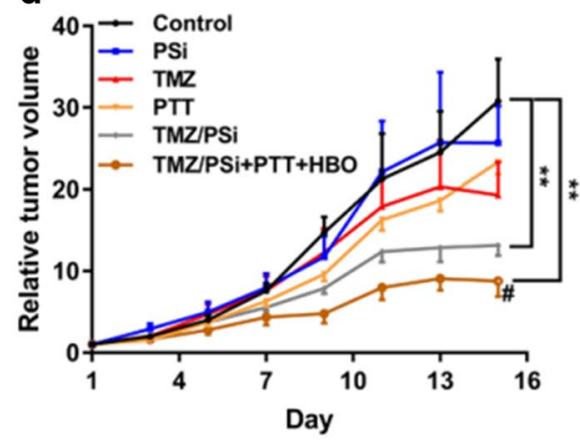

e

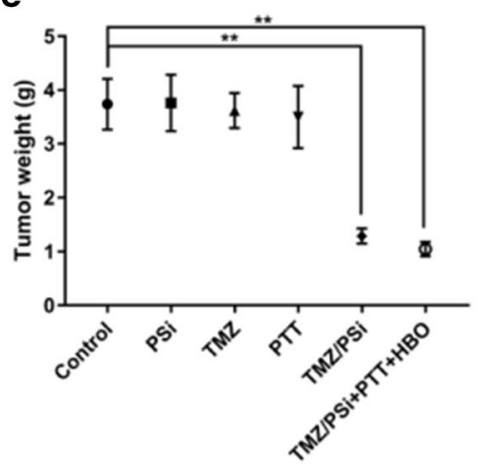

f

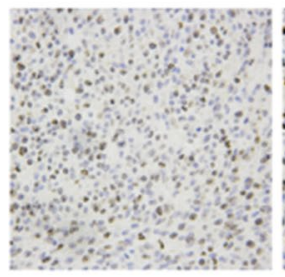

Control

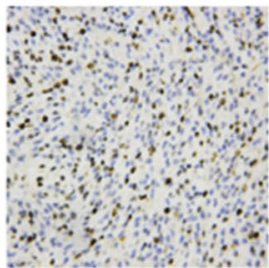

PSi

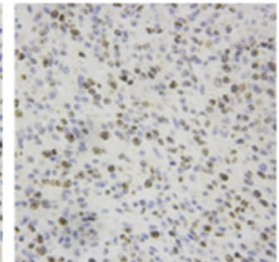

TMZ

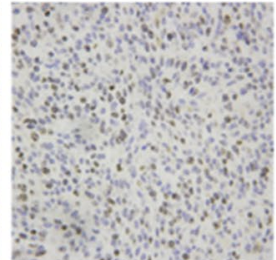

PTT

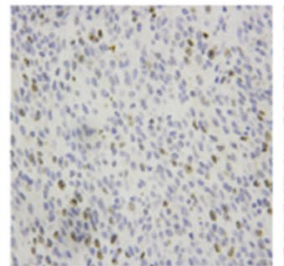

TMZ/PSi

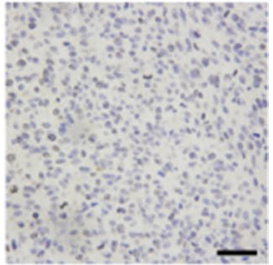

TMZIPSi $+\mathrm{PTT}+\mathrm{HBO}$

Fig. 6 Antitumor effects of TMZ/PSi NPs in combination with PTT and HBO in vivo. a Tumor thermal imaging exposed to NIR irradiation. $\mathbf{b}$ Tumor thermal curve exposed to NIR irradiation. c Tumors from mice after different treatments. Bar: $1 \mathrm{~cm}$. $\mathbf{d}$ Changes of tumor volume $\left(\mathrm{n}=5 ;{ }^{* *} \mathrm{P}<0.01\right.$,, TMZ/PSi vs TMZ/PSi + PTT + HBO, $\mathrm{P}<0.05)$. e Tumor weight $\left(\mathrm{n}=5\right.$; $\left.{ }^{*} \mathrm{P}<0.01\right)$. $\mathbf{f}$ Immunohistochemical staining of Ki-67, bar: $20 \mu \mathrm{m}$

hyperthermia by patients. Figure $6 \mathrm{~d}$ showed the relative tumor volume changes. There was no significant difference of tumor growth rate in PSi or PTT alone group, which suggested PSi or PTT had no obvious antitumor effect. Although free TMZ group had a tendency to inhibit the growth of tumors, there was no significant difference between the free TMZ group and control group, which indicated that free TMZ had little effect on tumor inhibition. However, the significant suppression of tumor growth was presented in TMZ/ PSi group and TMZ/PSi combined with PTT and HBO group. Compared to TMZ/PSi group, better antitumor effects were shown in the TMZ/PSi combined with PTT and HBO group ( ${ }^{\#} \mathrm{P}<0.05$ ) (Fig. 6c). The tumor weight changes were in agreement with the tumor size changes (Fig. 6e). There were no significant changes of mouse body weights (Additional file 1: Figure S7). Based on the change of tumor volume, the tumor inhibition rate was calculated. The inhibition rates of PSi, TMZ and PTT were $16.5 \%, 37.2 \%$ and $24.2 \%$ respectively, whereas $57.2 \%$ in TMZ/PSi and $71.5 \%$ in TMZ/ $\mathrm{PSi}+\mathrm{PTT}+\mathrm{HBO}$ were presented. Therefore, TMZ/ PSi has a better anti-tumor effect than TMZ in vivo. PTT and HBO enhancing the effectiveness of TMZ/ 
PSi, were useful as adjuvant therapy in the treatment of glioma. Our results disclosed that the combination treatment of TMZ/PSi NPs with PTT and HBO can efficiently augment the antitumor efficacy.

As shown in Fig. 6f, the proliferation of tumor cell (brown color) was relatively lower in the combination treatment than that in the other groups (Additional file 1: Figure S8). After H\&E staining of tissues, no evident pathological changes were found (Additional file 1: Figure S9). Therefore, combination treatment of TMZ/PSi with PTT and HBO is a potential strategy for glioma therapy.

\section{Expression of tumor stem-like markers in vivo}

Expression of tumor stem-like markers as well as other hypoxia related factors was determined in tumor tissues by the methods of immunohistochemistry and qRT-PCR. Studies have shown that low doses of TMZ can lead to chemoresistance in glioma cells [32, 37, 38]. As shown in Fig. $7 \mathrm{a}-\mathrm{c}$, compared with the control group, TMZ increased the expression of stemness and hypoxia related factors, which agrees with the reports. The expression of SOX2, Nestin, HIF- $1 \alpha$ and VEGF in tumor tissues from TMZ/PSi combined with PTT and HBO group were efficiently decreased compared with other groups, suggesting PTT and HBO could effectively help to amend
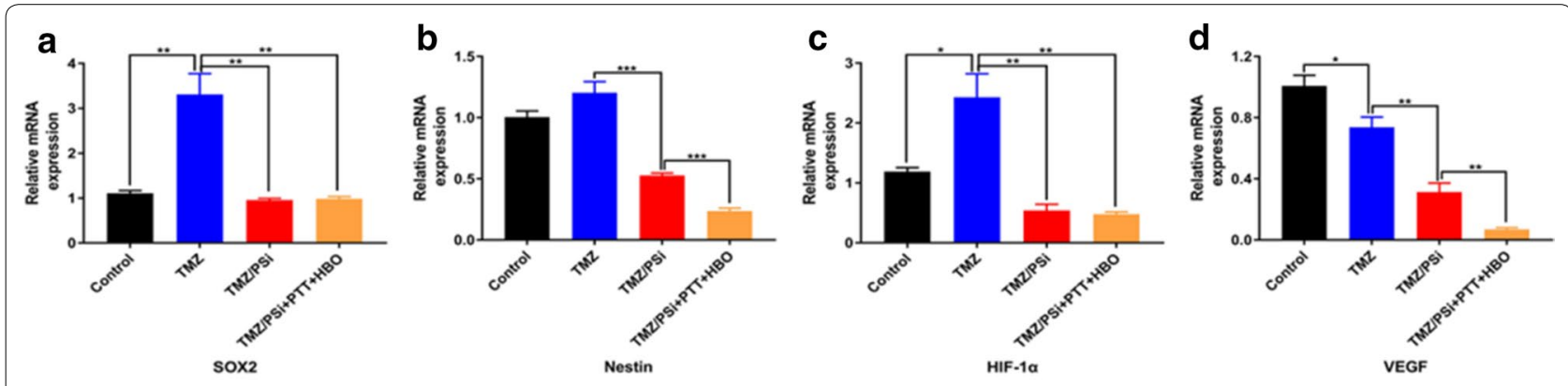

e

$$
\text { Control }
$$

PSi

TMZ
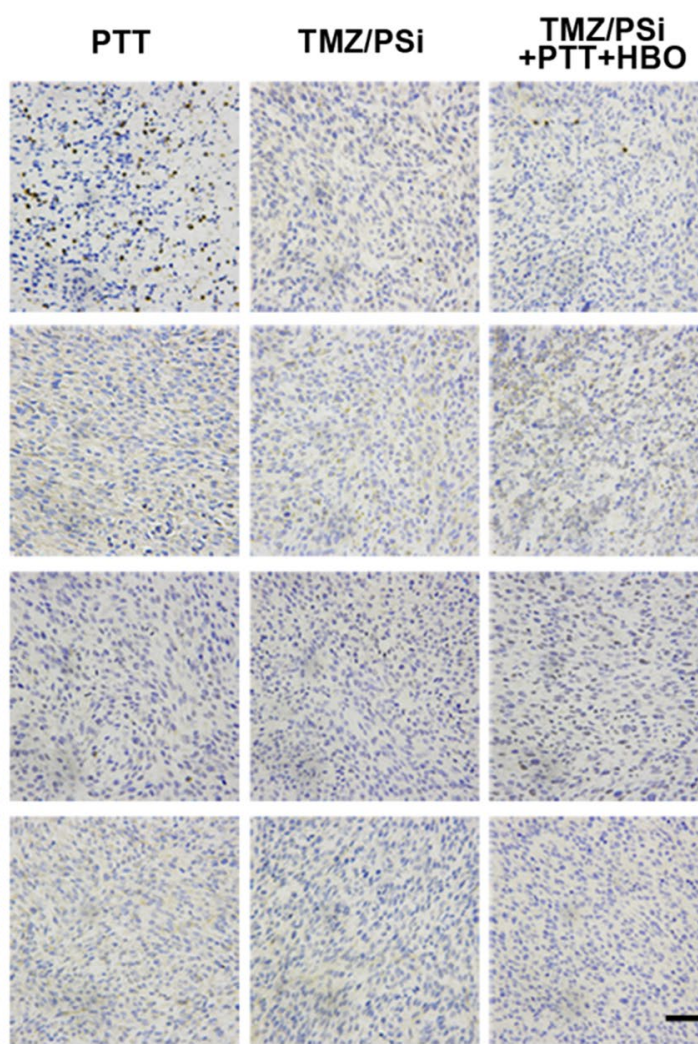

SOX2

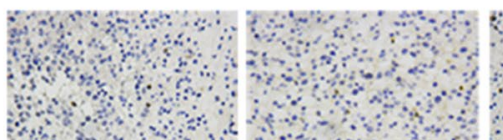

Nestin

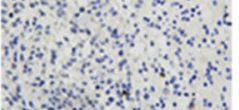
Mtotis
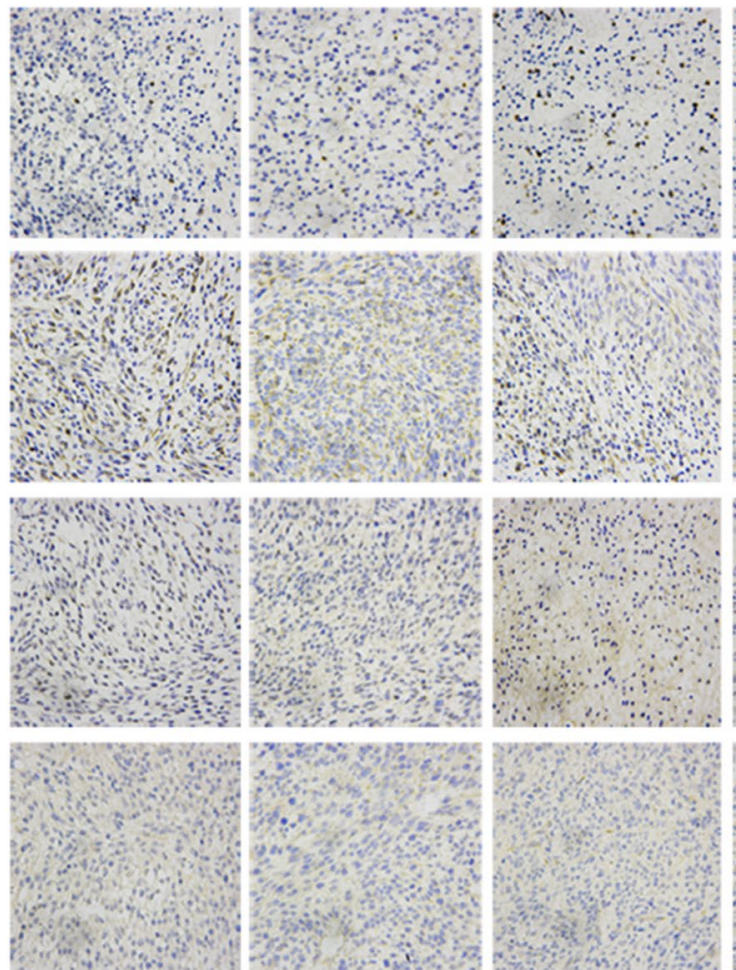

Fig. 7 Expression of tumor stem-like markers in vivo. a-d mRNA changes of SOX2, Nestin, HIF-1a and VEGF in C6 tumor tissues after combination treatment $\left(n=3 ;{ }^{*} P<0.05,{ }^{* *} P<0.01,{ }^{* * *} P<0.001\right)$. e Immunohistochemical staining for SOX2, Nestin, HIF-1a and VEGF of the tumors. Bar: $20 \mu \mathrm{m}$ 
the tumor stemness and hypoxia environment (Fig. 7). The results of immunohistochemical staining were in line with the results of qRT-PCR (Fig. 7e), which is similar with the results in vitro. Therefore, the combination treatment is an effective strategy against glioma.

\section{Conclusion}

How to reduce stemness and increase the drug sensitive is important for glioma therapy. In this study, HBO and mild thermotherapy can perfectly adjuvant the TMZ/ PSi to amend the hypoxia environment in tumor and enhance TMZ/PSi therapy on stem-like cells in glioma. The combination treatment would be a potential treatment for glioma therapy.

\section{Additional file}

Additional file 1: Table S1. List of primer sequences for mRNA analysis. Figure S1. The stability of TMZ/PSi in a week. Figure S2. The relative viability of $\mathrm{NCH}-421 \mathrm{~K}$ cells after treatment with different concentration of $\operatorname{TMZ}\left(n=5 ;{ }^{* * P}<0.01\right)$. Figure $\mathbf{S 3}$. The relative viability of $\mathrm{C} 6$ cells after treatment with different concentration of TMZ $\left(n=5\right.$; $\left.{ }^{* * * P}<0.001\right)$. Figure S4. The relative viability of C6 cells after treatment with PSi, TMZ, TMZ/ PSi, or TMZ/PSi + PTT under normoxia environment or normoxia + HBO $(n=5 ; * * P<0.001)$. Figure $\mathbf{S 5}$. The spheroid colony size of $\mathrm{NCH}-421 \mathrm{~K}$ cells after different treatments on day $7\left(n=4 ;{ }^{* *} p<0.01,{ }^{* * *} p<0.001\right)$. Figure S6. mRNA analysis in NCH-421K cells after $72 \mathrm{~h}$ treatments $(\mathrm{n}=$ $\left.3 ;{ }^{*} P<0.05,{ }^{* * P}<0.01,{ }^{* * * P}<0.001\right)$. Figure S7. Relative body weight of the mice $(n=5)$. Figure S8. Relative optical density in each tumor slices of immunohistochemical staining $\left(n=5 ;{ }^{* *} p<0.01\right.$, $\left.{ }^{* * *} p<0.001\right)$. Figure S9. Histological sections of the mouse hearts, livers, spleens, lungs and kidneys. Bar: $20 \mu \mathrm{m}$.

\section{Abbreviations}

PSi: porous silicon; TMZ: temozolomide; HBO: hyperbaric oxygen; CSC: cancer stem cell; ADMSC: adipose-derived mesenchymal stem cell; NIR: near-infrared; NPs: nanoparticles; PTT: photothermal therapy; TEM: transmission electron microscope; bFGF: basic fibroblast growth factor; EGF: epidermal growth factor; CCK-8: cell counting kit 8; qRT-PCR: quantitative real time polymerase chain reaction; GSCs: glioma stem cells; VEGF: vascular endothelial growth factor; HIF-1a: hypoxia inducible factor-1; H\&E: hematoxylin \& eosin staining.

\section{Authors' contributions}

$X Z$ designed and carried out experiments, analyzed data and wrote the manuscript. $X T$ and $L J$ conducted in vivo treatment and imaging analysis. QW, $Y Z$ and $X Y$ supervised entire project and involved in the designing of all experiments and revised the manuscript. ZZ and $\mathrm{MH}$ performed the PSi preparation. YL and XB performed cell culture. All authors read and approved the final manuscript.

\section{Competing interests}

The authors declare that they have no competing interests.

\section{Availability of data and materials}

All data generated or analyzed during this study are included in this manuscript.

\section{Consent for publication}

All authors agree to be published.

\section{Ethics approval and consent to participate}

The animal studies were approved by the Animal Experimentation Ethics Committee of College of Life Science and Technology, Huazhong University of Science and Technology. All procedures were carried out strictly with the animal care guidelines of the Science and Technology Department of Hubei Province.

\section{Funding}

This work was supported by The National Natural Science Foundation of China (No. 81573013), National Basic Research Program of China (2015CB931802) and National Natural Science Foundation of China (81627901).

\section{Publisher's Note}

Springer Nature remains neutral with regard to jurisdictional claims in published maps and institutional affiliations.

Received: 15 February 2019 Accepted: 27 March 2019

Published online: 01 April 2019

\section{References}

1. Tanaka S, Louis DN, Curry WT, Batchelor TT, Dietrich J. Diagnostic and therapeutic avenues for glioblastoma: no longer a dead end? Nat Rev Clin Oncol. 2013;10:14-26.

2. Wu G, Diaz AK, Paugh BS, Rankin SL, Ju BS, Li YJ, et al. The genomic landscape of diffuse intrinsic pontine glioma and pediatric non-brainstem high-grade glioma. Nat Genet. 2014;46:444-50.

3. Stupp R, Mason WP, van den Bent MJ, Weller M, Fisher B, Taphoorn MJB, et al. Radiotherapy plus concomitant and adjuvant temozolomide for glioblastoma. N Engl J Med. 2005;352:987-96.

4. Yu Q, Xue YX, Liu J, Xi Z, Li Z, Liu YH. Fibronectin promotes the malignancy of glioma stem-like cells via modulation of cell adhesion, differentiation, proliferation and chemoresistance. Front Mol Neurosci. 2018;11:130.

5. Seliger C, Luber C, Gerken M, Schaertl J, Proescholdt M, Riemenschneider $\mathrm{MJ}$, et al. Use of metformin and survival of patients with high-grade glioma. Int J Cancer. 2019;144:273-80.

6. Talukdar S, Pradhan AK, Bhoopathi P, Shen XN, August LA, Windle JJ, et al. MDA-9/Syntenin regulates protective autophagy in anoikis-resistant glioma stem cells. Proc Natl Acad Sci USA. 2018;115:5768-73.

7. Wang XX, Prager BC, Wu QL, Kim LJY, Gimple RC, Shi Y, et al. Reciprocal signaling between glioblastoma stem cells and differentiated tumor cells promotes malignant progression. Cell Stem Cell. 2018;22:514.

8. Mathieu J, Zhang Z, Zhou WY, Wang AJ, Heddleston JM, Pinna CMA, et al. HIF induces human embryonic stem cell markers in cancer cells. Cancer Res. 2011;71:4640-52.

9. Park SJ, Kim JG, Kim ND, Yang K, Shim JW, Heo K. Estradiol, TGF-1 and hypoxia promote breast cancer stemness and EMT-mediated breast cancer migration. Oncol Lett. 2016;11:1895-902.

10. Fotia C, Massa A, Boriani F, Baldini N, Granchi D. Hypoxia enhances proliferation and stemness of human adipose-derived mesenchymal stem cells. Cytotechnology. 2015;67:1073-84.

11. Gaelzer MM, dos Santos MS, Coelho BP, de Quadros AH, Simao F, Usach $V$, et al. Hypoxic and reoxygenated microenvironment: stemness and differentiation state in glioblastoma. Mol Neurobiol. 2017;54:6261-72.

12. Bowyer C, Lewis AL, Lloyd AW, Phillips GJ, Macfarlane WM. Hypoxia as a target for drug combination therapy of liver cancer. Anti-cancer Drug. 2017:28:771-80.

13. Ge X, Pan MH, Wang L, Li W, Jiang CF, He J, et al. Hypoxia-mediated mitochondria apoptosis inhibition induces temozolomide treatment resistance through miR-26a/Bad/Bax axis. Cell Death Dis. 2018;9:1128.

14. Wu X, Zhu YH, Huang W, Li JQ, Zhang BX, Li ZF, et al. Hyperbaric oxygen potentiates doxil antitumor efficacy by promoting tumor penetration and sensitizing cancer cells. Adv Sci. 2018;5:1700859.

15. Xie YY, Zeng XF, Wu X, Hu J, Zhu YH, Yang XL. Hyperbaric oxygen as an adjuvant to temozolomide nanoparticle inhibits glioma growth by inducing G2/M phase arrest. Nanomedicine. 2018;13:887-98. 
16. Mallory M, Gogineni E, Jones GC, Greer L, Simone CB. Therapeutic hyperthermia: the old, the new, and the upcoming. Crit Rev Oncol Hematol. 2016;97:56-64.

17. van der Zee J. Heating the patient: a promising approach? Ann Oncol. 2002;13:1173-84.

18. Song CW, Park HJ, Lee CK, Griffin R. Implications of increased tumor blood flow and oxygenation caused by mild temperature hyperthermia in tumor treatment. Int J Hyperther. 2005;21:761-7.

19. Tang JQ, Zhou HG, Hou XY, Wang LM, Li YX, Pang YY, et al. Enhanced antitumor efficacy of temozolomide-loaded carboxylated poly(amido-amine) combined with photothermal/photodynamic therapy for melanoma treatment. Cancer Lett. 2018:423:16-26.

20. Rao W, Wang H, Zhong A, Yu JH, Lu XB, He XM. Nanodrug-mediated thermotherapy of cancer stem-like cells. J Nanosci Nanotechnol. 2016;16:2134-42.

21. Lee C, Kim H, Hong C, Kim M, Hong SS, Lee DH, et al. Porous silicon as an agent for cancer thermotherapy based on near-infrared light irradiation. J Mater Chem. 2008;18:4790-5.

22. Ohguri T, Kunugita N, Yahara K, Imada H, Uemura H, Shinya N, et al. Efficacy of hyperbaric oxygen therapy combined with mild hyperthermia for improving the anti-tumour effects of carboplatin. Int J Hyperther. 2015;31:643-8.

23. Xia B, Wang B, Shi JS, Zhang Y, Zhang Q, Chen ZY, et al. Photothermal and biodegradable polyaniline/porous silicon hybrid nanocomposites as drug carriers for combined chemo-photothermal therapy of cancer. Acta Biomater. 2017;51:197-208.

24. Kotkovskiy GE, Kuzishchin YA, Martynov IL, Chistyakov AA, Nabiev I. The photophysics of porous silicon: technological and biomedical implications. Phys Chem Chem Phys. 2012;14:13890-902.

25. Xiao L, Gu L, Howell SB, Sailor MJ. Porous silicon nanoparticle photosensitizers for singlet oxygen and their phototoxicity against cancer cells. ACS Nano. 2011;5:3651-9.

26. Kaur B, Khwaja FW, Severson EA, Matheny SL, Brat DJ, Van Meir EG. Hypoxia and the hypoxia-inducible-factor pathway in glioma growth and angiogenesis. Neurooncology. 2005;7:134-53.

27. Yu ZY, Zhao G, Li PL, Li YQ, Zhou GT, Chen Y, et al. Temozolomide in combination with metformin act synergistically to inhibit proliferation and expansion of glioma stem-like cells. Oncol Lett. 2016;11:2792-800.
28. Man JH, Shoemake JD, Ma TP, Rizzo AE, Godley AR, Wu QL, et al. Hyperthermia sensitizes glioma stem-like cells to radiation by inhibiting AKT signaling. Cancer Res. 2015;75:1760-9.

29. Sun S, Lee D, Lee NP, Pu JKS, Wong STS, Lui WM, et al. Hyperoxia resensitizes chemoresistant human glioblastoma cells to temozolomide. J Neurooncol. 2012;109:467-75.

30. Shi Y, Guryanova OA, Zhou WC, Liu C, Huang Z, Fang XG, et al. Ibrutinib inactivates BMX-STAT3 in glioma stem cells to impair malignant growth and radioresistance. Sci Transl Med. 2018;10:eaah6816.

31. Liu J, Tan YH, Zhang HF, Zhang Y, Xu PW, Chen JW, et al. Soft fibrin gels promote selection and growth of tumorigenic cells. Nat Mater. 2012;11:734-41.

32. Lorz A, Lorenzi T, Hochberg ME, Clairambault J, Perthame B. Populational adaptive evolution, chemotherapeutic resistance and multiple anticancer therapies. ESAIM Math Model Numer Anal. 2013;47:377-403.

33. Arun S, Ravisankar S, Vanisree AJ. Implication of connexin30 on the stemness of glioma: connexin30 reverses the malignant phenotype of glioma by modulating IGF-1R, CD133 and CMyc. J Neurooncol. 2017;135:473-85.

34. Zhou XD, Wang XY, Qu FJ, Zhong YH, Lu XD, Zhao P, et al. Detection of cancer stem cells from the C6 glioma cell line. J Int Med Res. 2009;37:503-10.

35. Karbownik MS, Pietras T, Szemraj J, Kowalczyk E, Nowak JZ. The ability of hyaluronan fragments to reverse the resistance of C 6 rat glioma cell line to temozolomide and carmustine. Contemp Oncol. 2014;18:323-8.

36. Hong C, Lee J, Zheng H, Hong SS, Lee C. Porous silicon nanoparticles for cancer photothermotherapy. Nanoscale Res Lett. 2011;6:321.

37. Bocangel DB, Finkelstein S, Schold SC, Bhakat KK, Mitra S, Kokkinakis DM. Multifaceted resistance of gliomas to temozolomide. Clin Cancer Res. 2002;8:2725-34.

38. Hegi ME, Diserens AC, Gorlia T, Hamou MF, de Tribolet N, Weller M, et al. MGMT gene silencing and benefit from temozolomide in glioblastoma. N Engl J Med. 2005;352:997-1003.
Ready to submit your research? Choose BMC and benefit from:

- fast, convenient online submission

- thorough peer review by experienced researchers in your field

- rapid publication on acceptance

- support for research data, including large and complex data types

- gold Open Access which fosters wider collaboration and increased citations

- maximum visibility for your research: over $100 \mathrm{M}$ website views per year

At $\mathrm{BMC}$, research is always in progress.

Learn more biomedcentral.com/submissions 